
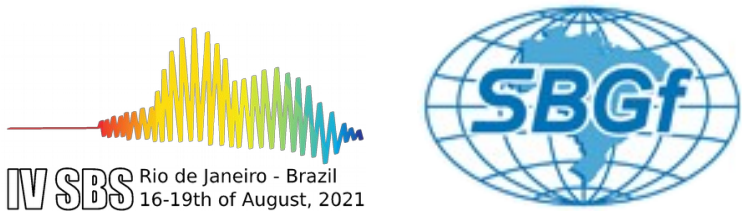

\title{
Sequência Sísmica em Miranda-MS, Novembro de 2015
}

Estevão Tadeu, UFMS/FAENG, Juliana de Carvalho Melo, UFMS/FAENG, Edna Facincani, UFMS/FAENG, Marcelo Bianchi, IAG-USP, Bruno Collaço, IAG-USP, Marcelo Assumpção, IAG-USP

Copyright 2021, SBGf - Sociedade Brasileira de Geofísica.

This paper was prepared for presentation during the $17^{\text {th }}$ International Congress of the Brazilian Geophysical Society held in Rio de Janeiro, Brazil, 16-19 August 2021.

Contents of this paper were reviewed by the Technical Committee of the $17^{\text {th }}$ International Congress of the Brazilian Geophysical Society and do not necessarily represent any position of the SBGf, its officers or members. Electronic reproduction or storage of any part of this paper for commercial purposes without the written consent of the Brazilian Geophysical Society is prohibited.

\section{Resumo}

A Bacia Sedimentar do Pantanal é uma depressão tectônica interior localizada entre os Estados de Mato Grosso e Mato Grosso do Sul (centro-oeste do Brasil) que possui idade quaternária e cobre uma área de aproximadamente $135.000 \mathrm{~km}^{2}$ e com altitudes entre 80 e $180 \mathrm{~m}$ acima do nível do mar. Na região da Bacia, próximo à cidade de Miranda, ocorreu em 1964 um dos maiores sismo registrados no Brasil com uma magnitude determinada de mb 5,4. Outro evento importante no contexto brasileiro ocorreu na região da cidade de Coxim, também dentro da Bacia do Pantanal, em junho de 2009, com magnitude de mb 4,8. Estudos realizados mostraram que os mecanismos focais de tais eventos tem relação com falhas inversas ou transcorrentes com componente inversa. Neste trabalho foi estudada uma sequência sísmica ocorrida entre os dias 5 e 15 novembro de 2015 ocorrida na região de Miranda. A sequência iniciou-se com um sismo precursor de magnitude ML 2,2 seguido, horas depois pelo sismo principal, de magnitude mR 4,0 e suas réplicas. No total, foram registradas treze réplicas, das quais cinco estão incluídas no catálogo brasileiro. Para determinar a intensidade do evento principal usou-se um questionário sísmico com doze perguntas. Foram obtidas 45 respostas que indicaram que a intensidade variou de I a VI na Escala Mercalli Modificada, sendo o valor máximo, uma possível localização do epicentro. O mecanismo focal determinado para o sismo de magnitude 4,0 foi obtido usando o ISOLA-GUI, no qual foi observado uma falha transcorrente. O Hypo71 foi utilizado para relocalizar o evento principal e as réplicas que foram registradas em mais de uma estação. Devido a baixa cobertura de estações, boa parte dos sismos secundários, foram registrados em somente uma estação. As distâncias epicentrais registradas variaram entre 50 e $130 \mathrm{~km}$. A sequência sísmica observada reforça que a sismicidade da Bacia Sedimentar do Pantanal é relevante no contexto brasileiro e pode ajudar a compreender a sua evolução recente. 